\section{CONGENITAL HEART DISEASE DISTRIBUTION IN A TERTIARY NEONATAL INTENSIVE CARE UNIT}

doi:10.1136/archdischild-2012-302724.1118

'A Dursun, ${ }^{2} \mathrm{~S}$ Ozgur, 'BS Karagol, 'N Hakan, 'N Karadag, 'B Aydin, 'A Zenciroglu, ${ }^{1} \mathrm{~N}$ Okumus, ${ }^{1} \mathrm{~S}$ Beken, ${ }^{2} \mathrm{~S}$ Karademir. ${ }^{1}$ Neonatology; ${ }^{2}$ Pediatric Cardiology, Dr Sami Ulus Maternity and Children's Health and Diseases Training and Research Hospital, Ankara, Turkey

Background \& aim Congenital heart malformation (CHM) is one of the most frequent and important abnormalities in newborns. In this study we retrospectively analyzed the frequency and distribution of the congenital heart diseases in our NICU.

Method Newborns hospitalized in NICU between 2005 and 2011 were retrospectively analyzed. Gestational age, birth weight, consanguinity, type of congenital heart disease extracted from the computerized database. CHMswere classified as follows; left-to-right shunt, obstructive, cyanotic with decreased pulmonary flow, cyanotic with increased pulmonary flow and others.

Results A total of 706 newborns were diagnosed as congenital heart disease during 7-year study period among the 7450 admission (9.5\%). Consanguinity rate was $22.3 \%$ and $30.4 \%$ of these were first degree relatives. $42.7 \%, 17.3 \%, 13 \%, 11.6 \%$ were leftto-right shunt, obstructive, cyanotic with decreased pulmonary flow, cyanotic with increased pulmonary flow and others, respectively. Most frequent heart malformations were ASD (25.5\%), VSD (12.6\%), Aortic coarctation (10.8\%), PDA (9.5\%), TGA (8.8\%), pulmonary atresia (8.2\%), AVSD (4.1\%), hypoplastic left heart $(3.8 \%)$, pulmonary stenosis $(3.1 \%)$, TOF $(2.5 \%) .37 \%$ of the newborns had at least one congenital malformation in other organ systems.

Conclusion ASD, VSD and aortic coarctation were most common congenital heart disease followed in our NICU.

\section{EVALUATION OF THE OT INTERVAL IN SMALL FOR GESTATIONAL AGE BABIES}

doi:10.1136/archdischild-2012-302724.1119

D Gürses, B Seyhan. Pediatrics, Pamukkale University, Faculty of Medicine, Denizli, Turkey

The objective of this study was to evaluate the QT interval and the effects of intrauterine malnutrition in small for gestational age babies (SGA). In this study, ECGs were recorded on their postnatal day five. Twenty-two SGA infants and 20 appropriate for gestational age babies (AGA) were evaluated. Heart rate, OT interval, QT interval corrected for heart rate (OTc), QT dispersion (QTD) and QTc dispersion (OTcD) were calculated for all infants.

The mean QT and QTc were $265 \pm 47 \mathrm{msec}$, and $379 \pm 45 \mathrm{msec}$ in the small for gestational age babies; whereas in the appropriate for gestational age babies the mean QT and OTc were $254 \pm 30 \mathrm{msec}$, and $367 \pm 33 \mathrm{msec}(\mathrm{p}>0.05)$. OTD was found $37 \pm 9 \mathrm{msec}$ and, $30 \pm 9$ msec in the SGA and AGA babies respectively. OTcD was found as $57 \pm 15 \mathrm{msec}$ and, $47 \pm 12 \mathrm{msec}$ in the SGA and AGA babies respectively. OTD and QTcD were found to be higher in the small for gestational age babies $(p<0.05)$. Significantly negative correlations were detected between the birth weight and QTD and $\mathrm{QTcD}$ $(\mathrm{p}<0.05 ; \mathrm{r}=-0.380$ and -0.360 , respectively).

The present findings suggest that QTD and QTcD values are significantly increased in SGA babies and it can be show deterioration of ventricular repolarization. Small for gestational age may be associated with an increased risk for the arrhythmia and sudden infant death.

\section{TISSUE DOPPLER IMAGING QUANTIFIES EARLY CHANGES IN PRETERM MYOCARDIUM}

doi:10.1136/archdischild-2012-302724.1120
1,2,3K Armstrong, 1,2,4E Molloy, ${ }^{3} 0$ Franklin. 'Neonatology, National Maternity Hospital; ${ }^{2}$ Research, National Children's Research Centre; ${ }^{3}$ Cardiology, Our Lady's Children's Hospital; ${ }^{4}$ Paediatrics, Royal College of Surgeons, Dublin, Ireland

Introduction Haemodynamic changes occurring during the fetal - neonatal transition may impact on global myocardial function in the first week of life. Tissue Doppler imaging (TDI) offers a novel technique to measure changes in systolic and diastolic function in neonates.

Aims To use TDI to assess myocardial function in preterm infants compared to gold standard measures.

Methods Preterm infants $<32$ weeks gestation were recruited. Echocardiography was carried out by a single observer (KA) using the GE Vivid I, on Day 1, 3-4 and Day 7. Clinical parameters were recorded at time of echocardiogram. Standard M mode echocardiography was used to determine shortening and ejection fraction. Myocardial velocities were obtained using a pulsed wave doppler sample from the lateral mitral/tricuspid annuli and intraventricular septum from an apical four chamber view. Peak systolic ( $\left.S^{\prime}\right)$, early diastolic (E') and late diastolic (A') velocities were recorded.

Results 140 echocardiograms were performed on 60 neonates with structurally normal hearts. Gestational age range- $23^{+6}-31^{+6}$ weeks. There was a significant increase in heart rate $(p=0.002)$ and systolic blood pressure over the 1st week. $(p=0.001)$. There was an increase in myocardial velocities across all measurements, with right ventricular early systolic and late diastolic velocities increasing significantly $(p<0.002)$. There was a significant increase in the left ventricle late diastolic velocities $(\mathrm{p}=0.036)$. There was no significant difference in shortening/ejection fraction over the first week.

Conclusion TDI offers a reliable measure of myocardial velocities over the first week. Current gold standard measures shortening/ ejection fraction showed no significant change in myocardial contractility however TDI demonstrated significant changes in both RV and LV systolic and diastolic velocities.

\section{AN ALTERNATIVE DRUG (PARACETAMOL) IN THE MANAGEMENT OF PATENT DUCTUS ARTERIOSUS IN IBUPROFEN RESISTANT OR CONTRAINDICATED PRETERM INFANTS}

doi:10.1136/archdischild-2012-302724.1121

${ }^{1} \mathrm{MY}$ Oncel, 'S Yurttutan, 'N Uras, ${ }^{2} \mathrm{~N}$ Altug, 'R Ozdemir, 'S Ekmen, '10 Erdeve, 1,3U Dilmen. 'Neonatology; ${ }^{2}$ Pediatric Cardiology, Zekai Tahir Burak Maternity Teaching Hospital; '3Pediatrics, YIIdırım Beyazıt University, Faculty of Medicine, Ankara, Turkey

Background and Aim The aim of this study was to evaluate the efficacy of paracetamol in preterm infants with patent ductus arteriosus (PDA) who failed to respond to ibuprofen treatment and/or for whom treatment with ibuprofen was contraindicated.

Methods Preterm infants with PDA who were ibuprofen-resistant and/or for whom ibuprofen treatment was contraindicated were started on paracetamol treatment with parental consent. Paracetamol was administered at a dose of $60 \mathrm{mg} / \mathrm{kg} /$ day, in 4 divided doses, for a period of 3-7 days. In the absence of closure of PDA, treatment was extended up to 7 days, after which repeat echocardiographic examination was performed.

Results A total of 8 preterm infants were included in the study with a median gestational age of 28.5 weeks (minimum-maximum: $23^{4 / 7}-36^{5 / 7}$ ) and a median birth weight of 995 grams (range 6302970). The first dose of paracetamol was given after a median of 9.5 days (range 5-27), for a median duration of 5 days (range 3-7). Median PDA diameter was 2.3 (range 2-3.5). Paracetamol resulted in successful closure of PDA in $7(87.5 \%)$ patients, while 1 patient $(12.5 \%)$ did not respond to treatment.

Conclusions To date, our case series is the largest to evaluate the efficacy of paracetamol for the management of PDA. We believe 
that paracetamol could be used as an alternative for infants who are either ibuprofen-resistant or for whom ibuprofen is contraindicated. Further prospective randomized-controlled trials are needed to evaluate the efficacy of paracetamol for the closure of PDA.

\section{THE EFFECT OF HEPARIN INFUSION ON DEVELOPMENT OF THROMBOSIS SECONDARY TO CARDIAC CATHETERIZATION}

doi:10.1136/archdischild-2012-302724.1122

'S Erol, ${ }^{2} \mathrm{G}$ Çınar, ${ }^{3} \mathrm{U} A$ Örün, 'B Aydın, 'D Dilli, 'A Dursun, 'S Beken, 'A Zenciroğlu, ${ }^{1} \mathrm{~N}$ Okumuş, ${ }^{3} \mathrm{~S}$ Karademir. ${ }^{1}$ Neonatology; ${ }^{2}$ Radiology; ${ }^{3}$ Pediatric Cardiology, Dr Sami Ulus Maternity and Children's Health and Diseases Training and Research Hospital, Ankara, Turkey

Background and Aim Cardiac catheterization is an important diagnostic tool. In this study, the frequency and the factors affecting the development of thrombosis were prospectively evaluated in neonates who were subjected to diagnostic and interventional cardiac catheterization.

Method 29 patients were enrolled in this study. Blood samples were taken for complete blood count, prothrombin, activated partial thromboplastin time, INR ratio, mutation of factor $V$ Leiden, prothrombin 20210 A, MTHFR C667 and A1298 before the procedure. $50 \mathrm{U} / \mathrm{kg}$ bolus of heparin was infused during catheterization and $20 \mathrm{U} / \mathrm{kg} /$ hour infusion of heparin was given to patients with clinically suspected thrombosis. Doppler was performed in all patients within 6 hours after catheterization.

Results Arterial catheterization in 16 cases, venous catheterization in 7 cases and both were applied in 6 cases. Arterial thrombosis in 7 patients and venous thrombosis in two patients was detected. It's observed that infusion of $20 \mathrm{U} / \mathrm{kg} / \mathrm{h}$ heparin had no effect on the development of arterial thrombosis. On the development of arterial and venous thrombosis, patient age, gender, diagnosis, treatments received prior to catheterization, hemoglobin and platelet count, PT, aPTT and INR values and Factor V Leiden, prothrombin $20210 \mathrm{~A}$, MTHFR C667, A1298 mutations were found as not impacting.

Conclusion There are no exact protocols for the prevention of thrombosis during and after catheterization. In this study, $50 \mathrm{unit} / \mathrm{kg}$ heparine bolus during catheterization and 20 unit $/ \mathrm{kg} /$ hour heparine infusion after catheterization did not prevent the development of thrombosis. Extensive studies are needed to determine the appropriate drugs and/or doses of preventive treatments.

\section{DO PATENT DUCTUS ARTERIOSUS AND ITS TREATMENT WITH ORAL IBUPROFEN AFFECT RENAL AND MESENTERIC TISSUE OXYGENATION IN PRETERM INFANTS?}

doi:10.1136/archdischild-2012-302724.1123

${ }^{1} \mathrm{~N}$ Guzoglu, 'FN Sari, 'R Ozdemir, 'S Oguz, 'N Uras, ${ }^{2} \mathrm{~N}$ Altug, 'U Dilmen. 'Neonatology; 2Pediatric Cardiology, Zekai Tahir Burak Maternity and Teaching Hospital, Ankara, Turkey

Background/Aim Patent ductus arteriosus (PDA) in preterm infants can result in serious hemodynamic changes causing respiratory, gastrointestinal and renal morbidities if not treated within the first week of life. We investigated the impact of PDA and its treatment with oral ibuprofen on regional renal and mesenteric oxygen saturation.

Methods 13 infants with PDA (gestational age $<32$ weeks), subsequently treated with oral ibuprofen, were monitored for mean arterial blood pressure, arterial oxygen saturation, near-infrared spectroscopy-determined regional renal and mesenteric oxygen saturation. The patients with PDA were matched for gestational age, birth weight, postnatal age, and severity of respiratory distress syndrome with infants without PDA, who served as control subjects.

Results Median renal and mesenteric oxygen saturation were similar in infants with PDA before and up to 12 hours after the start of ibuprofen therapy [renal oxygen saturation: $50 \%$ (25th-75th percentile: $29.5-65.5 \%$ ) vs. $54 \%$ (25th-75th percentile: $36-72.5 \%$ ), $p=0.556$; respectively); mesenteric oxygen saturation: $31 \%$ (25th-75th percentile: $19-38 \%$ ) vs. $32 \%$ (25th-75th percentile: $23.5-46 \%$ ), $p=0.239$; respectively]. Median renal and mesenteric oxygen saturation in control infants were also not significantly different in infants with PDA before and up to 12 hours after the start of ibuprofen therapy.

Conclusions A hemodynamically significant PDA and its adequate treatment with oral ibuprofen seem not to affect the renal and mesenteric perfusion and subsequent oxygen delivery in very low birth weight preterm infants.

\section{LEVOSIMENDAN RESCUE THERAPY IN NON- CARDIOSURGICAL NEONATES WITH HEART FAILURE: A CASE SERIES}

doi:10.1136/archdischild-2012-302724.1124

${ }^{1} \mathrm{~A}$ Tempera, ${ }^{2 \mathrm{M}}$ Piastra, ${ }^{2} \mathrm{E}$ Luca, ${ }^{3} \mathrm{G}$ De Rosa, ${ }^{1} \mathrm{E}$ Buffone, ${ }^{2} \mathrm{G}$ Conti, ${ }^{4} \mathrm{MP}$ De Carolis. ${ }^{1}$ Neonatal ICU, S.Camillo-Forlanini Hospital; ' $E$ Emergency Department, Pediatric ICU, ${ }^{3}$ Pediatric Cardiology, Department of Pediatrics; ${ }^{4}$ Neonatal ICU, Department of Pediatrics, Catholic University of the Sacred Heart, A. Gemelli Hospital, Roma, Italy

Background and Aims To report the successful use of the new inodilator levosimendan in 4 critically ill neonates with refractory heart failure. At present, no data are available on the use of levosimendan in newborns outside the cardiosurgical setting.

Methods Clinical chart review.

Results Neonates described in Table 1 were given LS due to severe refractory heart failure when standard treatment was ineffective and/or complications occurred. LS was administered as a continuous i.v. infusion $(0.2 \mathrm{mcg} / \mathrm{kg} / \mathrm{min}$ over the first $24 \mathrm{hrs})$. LS addition resulted in an improvement and/or stabilisation of hemodynamic status, with nearly normal restoration of heart function in $2 / 4$ infants. Patients with $\mathrm{PH}$ and RV enlargement could be weaned off from pulmonary vasodilators.

Conclusions In these full-term neonates with post-ischaemic low cardiac output/pulmonary hypertension and heart failure of infectious or metabolic origin, refractory to first line inotropic drugs, LS was a potent inotropic agent and a possible add-on therapy. As suggested, in the neonatal period LS may represent an ideal drug for immature myocardium characterized by a much more calcium dependent contractility than adults. Further studies are needed to evaluate the role of LS in refractory HF.

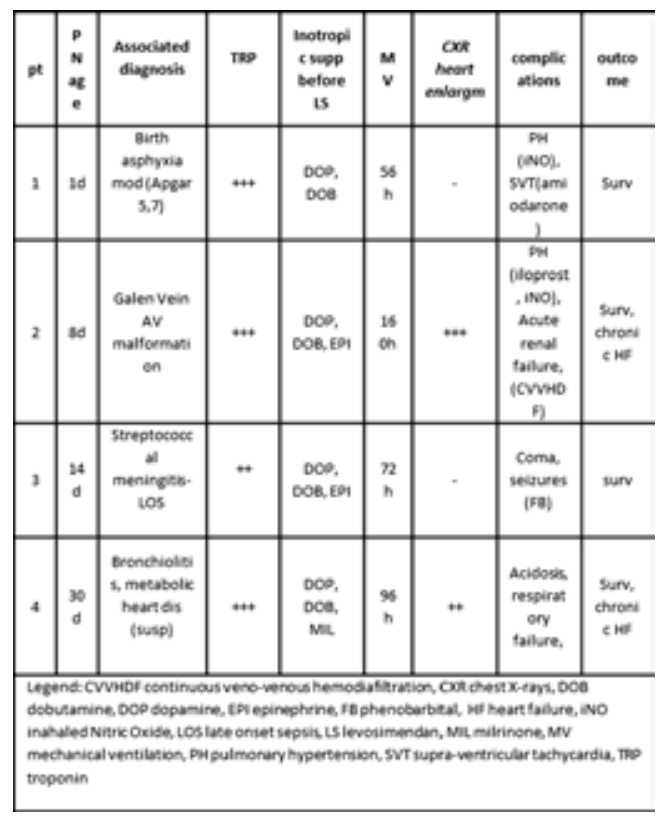

Abstract 1124 Figure 1 LS-neon 